\title{
GOLD NANOSHELL EFFECT ON LIGHT-HARVESTING IN LH2 COMPLEXES FROM PHOTOSYNTHETIC BACTERIA
}

\author{
I.Yu. Goliney, V.I. Sugakov, G.V. Vertsimakha * \\ Institute for Nuclear Research of National Academy of Sciences of Ukraine \\ 47 Nauky Pr., Kyiv, 03680, Ukraine
}

\begin{abstract}
The paper presents results of a theoretical study of the way a small gold nanoshell affects the efficiency of photosynthesis in the peripheral light-harvesting complex LH2 from photosynthetic bacteria. The total effect of the nanoshell is the interplay of the enhancement of the light absorption due to the strong coupling of excitons on the LH2 ring with the surface plasmon modes and the additional quenching of the excitations introduced by the proximity of the metal. The range of parameters for which a gold nanoshell enhances the total efficiency of the light harvestings has been determined.
\end{abstract}

\section{INTRODUCTION}

Recently a considerable amount of researches has been devoted to the study of optical properties of localized surface plasmons [1] due to potential applications in constructing biosensors [2], optical data storage devices [3], in surface-enhanced Raman scattering [4], in negative index materials [5], and superlensing [6]. Many interesting phenomena are caused by the strong interaction of the electronic subsystem of metal nanoparticles with the excitations of various systems such as semiconductor nanostructures and single molecules [7-11]. A small metal nanoparticle in the vicinity to these systems may essentially influence their optical absorption and emission, particularly, photosynthesis processes. The paper [12] described a particular example of a hybrid photosystem that incorporated a photosynthetic reaction center bound to gold and silver nanocrystals. The calculation showed that the rate of production of excited electrons inside the reaction center is strongly increased due to the plasmon resonance and the fast electron-hole separation. In the paper [13] the enhancement of optical transitions caused by the presence of a metal nanoparticle was analyzed for the photosystem I. In our previous paper [14] we studied the photosystem II exploring the theoretical possibility of affecting optical spectra and the quantum yield of the energy transfer in the peripheral light-harvesting complexes (LH2) from photosynthetic bacteria by placing a metal nanoshell (thin metallic coating deposited on dielectric core) nearby. It was shown that both the absorption of the excitations and the total yield of the excitation transfer in the light harversting antenna in the vicinity to a silver nanoparticle grew in a certain range of parameters. The consideration of the nanoparticle influence on delocalized states (excitons) of a photosynthetic system was carried out in [14]. The effect of the enhancement of the light in the presence of a nanoparticle is connected with the creation of mixed states of the molecular and the surface plasmon nature and is due to the large oscillation strength of the plasmon excitation. The effect peaks in the case of the resonance between the plasmon and the molecular levels. In order to reach the resonance, a nanoshell is suggested to use instead of a solid nanoparticle. There are two branches of nanoshell energy states [15] and the plasmon mode frequency of the lower branch may be shifted to infrared by choosing a proper ratio of the core radius to the shell thickness.

The present paper reports results of the research undertaken as a continuation of the study published in [14], extended to gold nanoparticles. The paper [14] presented results of the calculations carried out for a silver nanoshell. Gold is another common material for plasmonic studies. The inert gold surface provides several advantages for biosensing applications including biocompatibility and noncytotoxicity as well as developed synthesis technology $[16,17]$. Additionally, gold has a lower value of the plasmon frequency which 
makes the requirements to the aspect ratio of the nanoshell less strict. On the downside, surface plasmon peaks for gold nanoparticles are wider because of the increased damping. Besides the change of the material, the research of the present paper introduces a new feature in comparison to [14], namely, the dependence of the damping in a nanoshell on its radius and aspect ratio. The major contribution to the relaxation of the collective excitations in the metallic systems of small size comes from the scattering on the surface. The surface of the thin coatings of the nanoshells is relatively large for the same number of electrons. Therefore, it is the main factor in determining quenching of the excitations.

\section{STRUCTURE OF THE LH2-NANOSHELL SYSTEM. MAIN INTERACTIONS. METHOD OF SOLUTION}

Light-harvesting is the initial stage of the photosynthesis, when the energy of light is absorbed by pigments of ingeniously arranged molecular complexes before being further transferred to the reaction centers, where it is converted into stable charge separation states $[18,19]$. In most purple bacteria, a photosynthetic unit contains two types of lightharvesting complexes: LH1, which surrounds the reaction center, and $\mathrm{LH} 2$, which transfers energy to the reaction center through LH1 [20-22]. Both types of light harvesting complexes are composed of aggregates of bacteriochlorophyll (BChl) molecules symmetrically arranged in rings. The excitation energy is not localized on a particular pigment molecule; it can travel from one chlorophyll molecule on the ring to another before jumping to a next ring or to a reaction center. The symmetry of the molecule arrangement of such systems manifests itself in a well-expressed excitonic character of the excited states.

The X-ray structure of LH2 from Rhodopseudomonas acidophila reveals that this complex consists of two rings of BChl's, each of them is responsible for absorption either at 800 (the so-called B800 band) or at $850 \mathrm{~nm}$ (B850 band) [21-23]. In the rings which form $\mathrm{B} 850$ band, the distances between molecules are small, the interaction between molecules is great and the excitation has nature of the Frenkel exciton $[19,24]$. In Rhodopseudomonas acidophila, in the ring $\mathrm{B} 850$ of $\mathrm{LH} 2$ complexes, the dipole transition moments of the adjacent molecules are of the opposite directions, thus, the ring may be presented as consisting of 9 closely spaced $\mathrm{BChl}$ dimer unit cells and having C9 symmetry.

We consider a system consisting of $\mathrm{N}$ molecules arranged in a ring and a metallic nanoshell in its vicinity (Fig. 1). We suppose that all molecules are equivalent and can assume two different possible orientations. We shall designate the position of a molecule by a number $n$ $(n=1,2, \ldots, N / 2)$ and the type of the orientation by an index $\alpha(\alpha=1,2)$.

The problem of the enhancement of the light absorption by the $\mathrm{B} 850$ ring of $\mathrm{LH} 2$ complexes by a gold nanoparticle is similar to that for the silver nanoparticle previously considered in [14]. Therefore, in this paper we will omit the detailed theory, limiting ourselves with the expressions for the major interactions, the outline of the solution technique and the analysis of results. The quantum mechanical consideration relies on the procedure of secondary quantization of the surface plasmon modes developed in $[9,25]$.

Electronic states of the system is described by the Hamiltonian

$$
H=H_{r}+H_{p}+V_{p r},
$$

where $H_{r}$ is the Hamiltonian of the molecular ring, $H_{p}$ is that of the plasmon modes of the nanoparticle and term $V_{p r}$ stands for the interaction.

Excitonic states of the system are welldefined in the Heitler-London approximation and the corresponding Hamiltonian $H_{r}$ can be given by [18]:

$$
H_{r}=\sum_{n, \alpha} H_{n \alpha}^{0}+\sum_{\substack{n \alpha \neq n^{\prime} \alpha^{\prime} \\ \alpha, \alpha^{\prime}}} V_{n \alpha, n^{\prime} \alpha^{\prime}} B_{n \alpha}^{+} B_{n^{\prime} \alpha^{\prime}},
$$

where $H_{n \alpha}^{0}=E_{\alpha} B_{n \alpha}^{+} B_{n \alpha}$ is the Hamiltonian of a separate molecule ( $E_{\alpha}$ is the energy of the excitation of a molecule with the orientation $\alpha$, which can be different due to the difference of their surroundings, $B_{n \alpha}^{+}$and $B_{n \alpha}$ are creation and annihilation operators of the electronic excitation on $n \alpha$ molecule), the second term in (2) describes the resonance interaction of the excitation between $n$-th molecule with orientation $\alpha$ and the $n^{\prime}$ th molecule with orientation $\alpha^{\prime}$. Due to the presence of two molecules with different orientations in the ring, 
the exciton band splits into two Davydov components [18]. The exciton spectrum of the standalone molecular ring (the system with Hamiltonian $H_{r}$ ) was a subject of multiple studies $[18,19,26-30]$. The excited states are delocalized and the creation of the states is described by the creation operators $B_{k i}^{+}=\sum_{n, \alpha} a_{n}^{k i} B_{n \alpha}^{+}$. For calculations, the interaction between molecules was chosen within dipole-dipole approximation with the value of the transition dipole moment typical for BChl molecule in the protein $p_{0 f}=6.3 D$ [18].

The other parameters were chosen as follows: $E_{1}=12500 \mathrm{~cm}^{-1}, E_{2}=12800 \mathrm{~cm}^{-1}$ [31]. The spectrum has discrete character. It can be shown that only two states are excited by light in the dipole approximation.

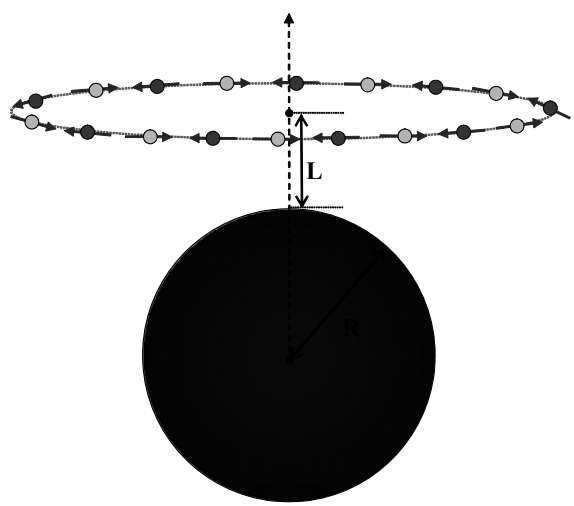

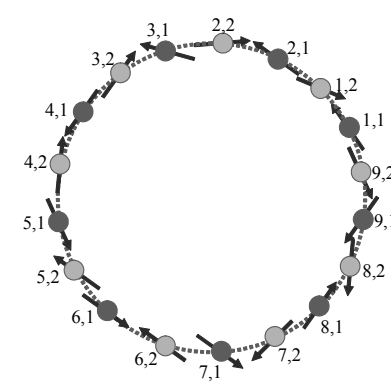

$b$

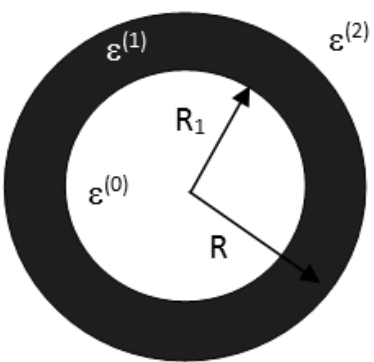

c

Fig. 1. Schematic structure of the system composed of metallic nanoshell and B850 ring (a); B850 ring schematic structure: arrows represent dipole moment orientations of molecules $(b)$; the metallic nanoshell structure $(c)$

We will consider a spherical nanoshell with the inner and outer radii denoted as $R_{1}$ and $R$, respectively, and the dielectric constants of the dielectric core, metal and matrix $\varepsilon^{(0)}$, $\varepsilon^{(1)}(\omega)=\varepsilon_{m 0}-\omega_{p}^{2} / \omega^{2}$ and $\varepsilon^{(2)}$, respectively

(Fig. 1c), where $\varepsilon_{m 0}$ is the frequency independent part of the dielectric function of metal, $\omega_{p}$ is the plasmon frequency. For the calculations we used the following parameters: the plasma frequency and the dielectric constant for gold $\hbar \omega_{p}=8.55 \mathrm{eV}$ [32] and $\varepsilon_{m 0}=8.9$ [33], respectively, $\varepsilon^{(2)}=1.8$.

Interaction of the ring of molecules with the nanoparticle is equal to

$$
V_{p r}=\sum_{n, \alpha} \nabla \hat{\phi}_{n \alpha} \hat{\vec{p}}_{n \alpha},
$$

where $\hat{\vec{p}}_{n \alpha}$ is the operator of the dipole transition of a molecule on the ring and $\widehat{\phi}_{n \alpha}$ is the operator of potential created by the nanoparticle in the environment medium in terms of the creation and annihilation operators $\widehat{A}_{l m}^{+}$and $\widehat{A}_{l m}$.

\section{CALCULATIONS AND DISCUSION}

The wave function of joint state of Hamiltonian (1) may be presented as a superposition of two states: the surface plasmon and the exciton in the ring

$\Psi_{l_{k} k i}=\alpha_{0, k i} B_{k i}^{+}|0\rangle+\beta_{l m, 0} A_{l m}^{+}|0\rangle$. 
The coefficients $\alpha_{0, \mathrm{ki}}$ and $\beta_{\mathrm{lm}, 0}$ are determined from solution of Schrödinger equation with Hamiltonian (1). They are obtained in [14].

We considered only the case when the metal particle is situated on the symmetry axis of the ring and the symmetry of the problem is not disturbed. Also, the disorder in arrangement of the molecules in the ring was not taken into account. The disorder should lead to the broadening of the lines, which is, however, smaller than the damping introduced by a metal particle.

The surface plasmons of the nanoparticle bind with the same exciton states which are excited by the light in the dipole approximation. This is the result of the chosen nanoparticle position not to disturb the system symmetry.

The calculations showed the value of the interaction induced shift of the exciton level in the ring to be small (the value of the order of several $\mathrm{meV}$ ). Despite the small value of the shift of the energy levels, the effect of the resonance interaction on optical transitions is important, because even a small admixture of the plasmon state to the exciton wave function significantly increases the probability of optical transition due to the giant value of the dipole transition moment of the surface plasmon.

The size of the considered system is significantly less than the wavelength of an electromagnetic wave in the optical region of the spectrum. In this case, the problem may be studied within the dipole approximation and the matrix element of the optical transition is proportional to the matrix element of the total dipole moment of the system, namely, to the sum of the operator $\widehat{\vec{P}}_{r}$ of the dipole of all molecules of the ring and the operator $\widehat{\vec{P}}_{p}$ of the dipole moment of the nanoparticle:

$\widehat{\vec{P}}=\widehat{\vec{P}}_{r}+\widehat{\vec{P}}_{p}$.

The calculations of the transition dipole moment are described in detail in [14]. When performing the calculations, we took into account the damping of the surface plasmon states introducing the imaginary part to the plasmon energy $\hbar \omega_{l m} \rightarrow \hbar \omega_{l m}-i \Gamma$. This nonradiative damping arises as a result of interaction between plasmon modes and other states of the electronic spectrum of the metal. It is known that when the size of the nanostructure becomes comparable with the mean free path of the conduction electrons, the damping begin to deviate from the bulk value because the scattering of carriers on metallic surfaces becomes important. The dependence of the damping constant on the thickness of the metallic layer of the nanoshell $a=R-R_{1}$ can be written as $\Gamma(a)=\Gamma_{0}+A \frac{v_{F}}{a}[34]$, where $\Gamma_{0}$ is the damping for the corresponding bulk material (we used the value $\Gamma_{0}=0.026 \mathrm{eV}$ for gold [32] ), $A$ is a dimensionless parameter the value of which is typically less than one, $v_{F}$ is the Fermi velocity (for gold $A=0.13$ and $v_{F}=1.41 \cdot 10^{6} \mathrm{~m} / \mathrm{s}$ [35]). The excitons on a ring are affected by this damping when hybridized with plasmon modes. Such damping is much stronger than the linewidth of the molecular excitation and therefore the latter was considered negligible. Thus, in our model the lifetime of the hybrid state is determined only by the quenching in the metal which arises as a result of the mixing of exciton and plasmon states.

In the following figures we present the ratio of transition dipole moment of the hybrid state and the transition dipole moment of the ring excitation $\delta=|P|^{2} /\left|P_{r}\right|^{2}$. The modulus squared of the transition dipole moment is proportional to the optical absorption, so $\delta$ determines the enhancement magnitude. The enhancement decreases with increasing the distance between the nanoparticle and the ring and also rises with increasing the nanoshell radius (Figs. 2, 3). As can be seen, the interaction may increase the absorption by a factor of two. Additionally, Figs. 2 and 3 present the linewidth of the level $\gamma$ determined by the quenching of the excitation in the nanoshell.

The effectiveness of the light-harvesting by the ring is determined by the rate of the excitation transfer to the reaction center. The nanoshell introduces an alternative decay pathway. The number of the excitons which transfer from this particular molecular ring per unit time may be estimated as $\left(\frac{d n}{d t}\right)_{0}=I_{0}-\frac{n_{0}}{\tau_{t r}}$. When a nanoparticle is placed in the vicinity to the ring, this equation should be modified 
to $\left(\frac{d n}{d t}\right)_{1}=I_{1}-\frac{n_{1}}{\tau_{t r}}-\frac{n_{1}}{\tau_{m}}$. Here $n_{0}, I_{0}$ and $n_{1}$,

$I_{1}$ are the exciton populations and the excitation rates in two cases: without and with the nanoshell, respectively, $\tau_{t r}$ is the time of the exciton transfer to other protein complexes (to the reaction center) in light-harvesting antenna (transfer between LH2 complexes and from LH2 to LH1 takes $1.5-5$ ps $[36,37]), 1 / \tau_{m}=\operatorname{Im} E / \hbar$ is the level broadening due to the presence of the nanoparticle.

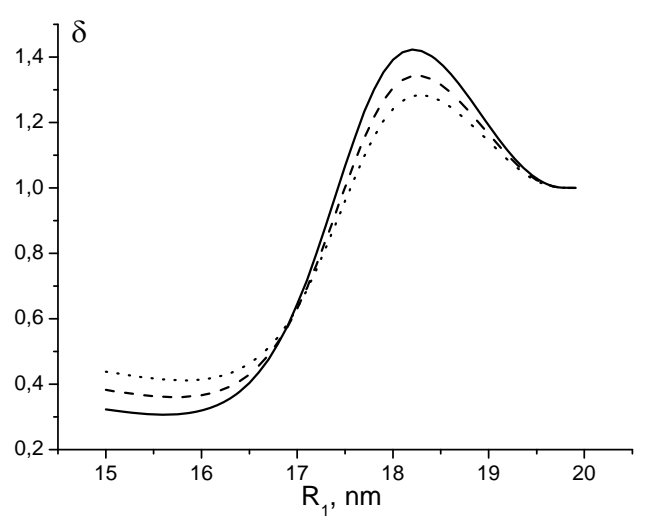

$a$

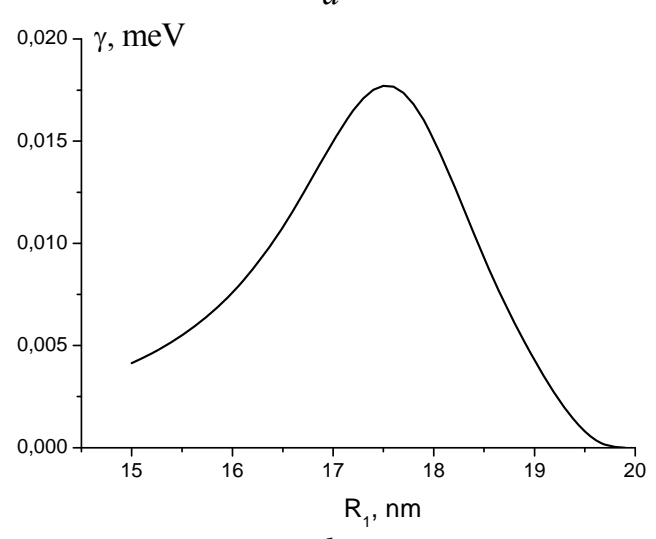

b

Fig. 2. Enhancement of absorption as function of the core radius for the nanoparticle with $R=20 \mathrm{~nm}$, $\mathrm{L}=1.5 \mathrm{~nm}$ (solid curve), $2.5 \mathrm{~nm}$ (dashed curve),

$23.5 \mathrm{~nm}$ (dotted curve), $\varepsilon^{(0)}=2-(a)$; linewidth of the energy level for the same parameters of the system and $\mathrm{L}=1.5 \mathrm{~nm}-(b)$

To estimate the relative enhancement of the rate of the light harvesting, we have calculated the ratio $\kappa \equiv n_{1} / n_{0}=\left(I_{1} / I_{0}\right) \tau_{m} /\left(\tau_{m}+\tau_{t r}\right)$. The photosynthesis would gain from the metal particle if $\kappa>1$. As seen in Fig. 4, the gain may be either positive or negative depending on the parameters and the position of the nanoshell.

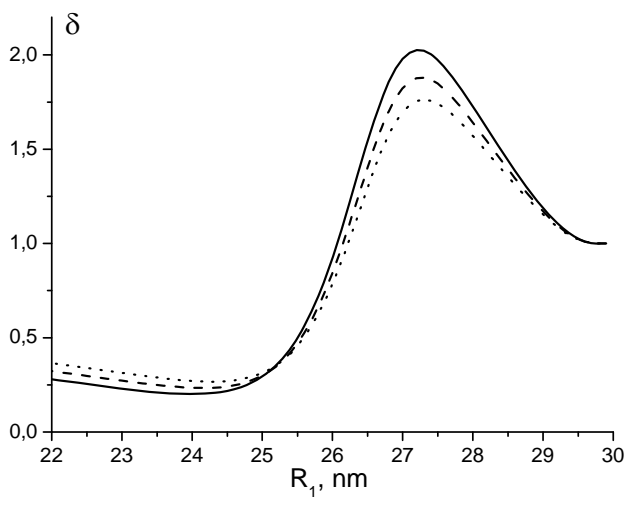

$a$

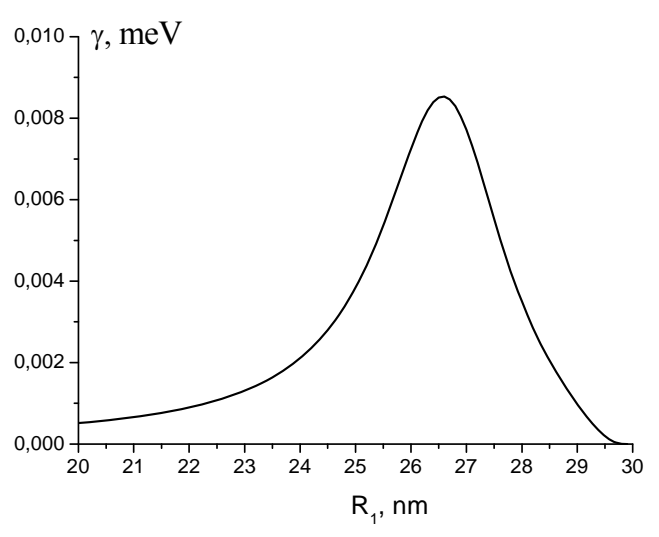

$b$

Fig. 3. Enhancement of absorption as function of the core radius for the nanoparticle with $R=30 \mathrm{~nm}$, $\mathrm{L}=1.5 \mathrm{~nm}$ (solid curve), $2.5 \mathrm{~nm}$ (dashed curve), $3.5 \mathrm{~nm}$ (dotted curve), $\varepsilon^{(0)}=2-(a)$; bandwidth of the energy level for the same parameters of the system, $\mathrm{L}=1.5 \mathrm{~nm}-(b)$

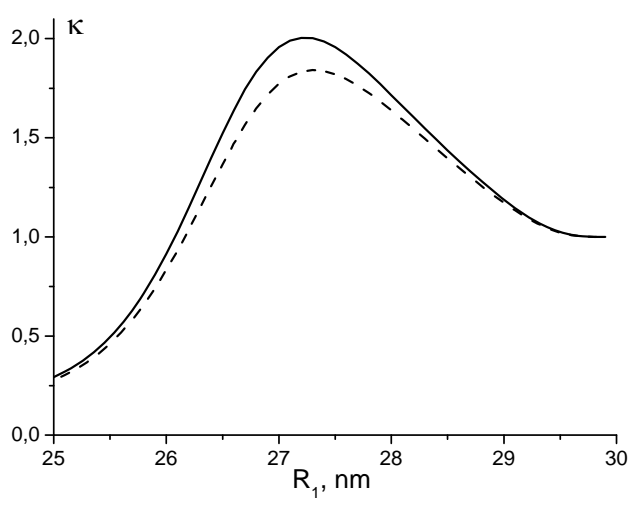

Fig. 4. Enhancement of the rate of the excitation transfer to other pigment-protein complexes in the photosynthetic antenna vs the radius of the nanoshell core R1. The radius of the particle $\mathrm{R}=30 \mathrm{~nm}$, the distance from the surface of the nanoparticle from the plane of the ring $\mathrm{L}=1.5 \mathrm{~nm}, \tau_{t r}=10^{-12} \mathrm{~s}$ (solid curve) and $\tau_{t r}=10^{-11} \mathrm{~s}$ (dashed curve), $\varepsilon^{(0)}=2$ 


\section{CONCLUSIONS}

As a continuation of the previous paper [14] we present a theoretical study on the effect of a gold nanoparticle with a dielectric inclusion inside (nanoshell) on the B850 band of the peripheral light harvesting complexes (LH2) from photosynthetic bacteria. Mixing of exciton states with the surface plasmon states may increase the optical absorption of the hybrid system due to the "borrowing" from the very high dipole plasmon transition intensity by the intensity of the exciton transition. The enhancement of the absorption rate due to the hybridization of the molecular excitations with the surface plasmons competes with the enhancement of the exciton damping induced by a metal particle. The nanoshell size dependence of the plasmon state damping was taken into account. The parameters of the gold nanoshell required to increase the effectiveness of the light harvesting have been estimated on the base of the kinetics of the exciton transfer to the molecular entities further in the photosynthetic antenna. In spite of the fact that the gold nanoparticle has the surface plasmon frequency closer to the absorption frequency of the B850 band of the LH2 complex than the silver surface plasmon frequency, effects of the enhancement are similar for both materials. This is connected with stronger value of damping in the gold. The advantage of the gold as the material for the coating of the nanoshell is, however, less strict requirements to the thickness of the outer metallic layer of the nanoshell.

The authors are grateful to prof. L. Valkunas for attracting their attention to the photosynthesis.

\section{REFERENCES}

1. Zayats A.V., Smolyaninov I.I., Maradudin A.A. Nano-optics of surface plasmon polaritons // Phys. Rep. - 2005. V. 408, N 3-4. - P. 131-314.

2. Aslan K., Lakowicz J.R., Geddes C.D. Plasmon light scattering in biology and medicine: new sensing approaches, visions and perspectives // Curr. Opin. Chem. Biol. 2005.- V. 9, N 5. - P. 538-544.

3. Tominaga J., Mihalcea C., Buechel D. et al. Local plasmon photonic transistor // Appl. Phys. Lett. - 2001. - V. 78, N 17. - P. 2417-2419.
4. Kneipp K., Wang Y., Kneipp H. et al. Single molecule detection using surface-enhanced Raman scattering (SERS) // Phys. Rev. Lett. - 1997.- V. 78, N 9. - P. 1667-1670.

5. Shalaev V.M., Cai W.S., Chettiar U.K. et al. Negative index of refraction in optical metamaterials // Opt. Lett. - 2005. - V. 30, N 4. - P. 3356-3358.

6. Pendry J.B. Negative refraction makes a perfect lens // Phys. Rev. Lett. - 2000. V. 85, N 11. - P. 3966-3969.

7. Zhang W., Govorov A.O., Bryant G.W. Semiconductor-metal nanoparticle molecules: hybrid excitons and non-linear Fano effect // Phys. Rev. Lett. - 2006. - V. 97, N 14. P. 146804 (1-5).

8. Sadeghi S.M. Plasmonic metaresonances: Molecular resonances in quantum dot-metallic nanoparticles conjugates // Phys. Rev. B. 2009. - V. 79, N 23. - P. 233309 (1-4).

9. Sugakov V.I., Vertsimakha G.V. Localized exciton states with giant oscillator strength in quantum well in vicinity of metallic nanoparticle // Phys. Rev. B. - 2010. V. 81, N 23. - P. 235308 (1-9).

10. Anger P., Bharadwaj P., Novotny $L$. Enhancement and quenching of singlemolecule fluorescence // Phys. Rev. Lett. 2006. -V. 96, N 11. - P. 113002 (1-4).

11. Kühn S., Hakanson U., Rogobete L., Sandoghdar $V$. Enhancement of singlemolecule fluorescence. Using a gold nanoparticle as an optical nanoantenna // Phys. Rev. Lett. - 2006.- V. 97, N 1. P. 017402 (1-4).

12. Govorov A., Carmeli I. Hybrid structure composed of photosynthetic system and metalanoparticles: plasmons enhancement effect // Nano Lett. - 2007. - V. 7, N 3. P. 620-625.

13. Mackowski S. Hybrid nanostructures for efficient light harvesting // J. Phys.: Condens. Matter. - 2010. - V. 22, N 19. P. 193118-193122.

14. Goliney I.Yu. Sugakov V.I., Valkunas L. Vertsimakha G.V. Effect of metal nanoparticles on energy spectra and optical properties of peripheral light-harvesting LH2 complexes from photosynthetic bacteria // Chem. Phys. - 2012. - V. 404. - P. 116-122.

15. Prodan E., Norlander P. Structural tunability of the plasmon resonances in 
metallic nanoshells // Nano Lett. - 2003. V. 3, N 4. - P. 543-547.

16. Kalele S., Gosavi S.W., Urban J. Kulkarni S.K. Nanoshell particles: synthesis, properties and applications // Curr. Sci. 2006. - V. 91, N 8. - P. 1038-1052.

17. Erickson T.A., Tunnell J.W. Gold nanoshells in biomedical applications // Nanomaterials for the Life Science. - Mixed Metal Nanomaterials WILEY-VCH, Weinheim V. 3. - 2009. - P. 1-44.

18. Blankenship R.E. Molecular Mechanisms of Photosynthesis. - Malden: Wiley-Blackwell, 2002. - $321 \mathrm{p}$.

19. $H u X$., Schulten $K$. How nature harvests sunlight // Phys. Today. - 1997. - V. 50, N 8. - P. 28-34.

20. Van Grondelle R., Novoderezhkin V.I. Photosynthesis: Quantum design for a light trap // Nature. - 2010. - V. 463, N 7281. P. 614-615.

21. Papiz M.Z., Prince S.M., HawthornthwaiteLawless A.M. et al. A model for the photosynthetic apparatus of purple bacteria. Trends in plant // Science. - 1996. - V. 1, N 6. - P. 198-206.

22. McDermott G., Prince S.M., Freer A.A. et al. Crystal-structure of an integral membrane light-harvesting complex from photosynthetic bacteria // Nature. - 1995. -V. 374, N 6522. - P. 517-521.

23. Koepke J., Hu X., Muenke C. et al. The crystal structure of the light-harvesting complex II (B800-850) from Rhodospirillum molischianum // Structure (London). - 1996. - V. 4. - P. 581-597

24. Novoderezhkin V., Razjivint A. Exciton dynamics in circular aggregates: application to antenna of photosynthetic purple bacteria // Biophys. J. - 1995. - V. 68, N 3. P. 1089-1100.

25. Goliney I.Y., Sugakov V.I. Rare-gas precipitates in metals as quantum dots for polaritons // Phys. Rev. B. - 2000. - V. 62, N 16. - P. 11177-11184.

26. Urboniene V., Vrublevskaja O., Gall A. et al. Temperature broadening of LH2 absorption in glycerol solution // Photosynth. Res. 2005. - V. 86, N 1-2. - P. 49-59.

27. Urboniene V., Vrublevskaja O., Trinkunas G. et al. Solvation effect of bacteriochlorophyll excitons in light-harvesting complexe LH2 //
Biophys. J. - 2007. - V.93, N 6. P. 2188-2198.

28. Mostovoy M.V., Knoerster J. Statistics of optical spectra from single-ring aggregates and its application to LH2 // J. Phys. Chem. B. - 2000. - V. 104. - P. 12355-12364.

29. Gordell R.J., Konler J. Use of singlemolecule spectroscopy to tackle fundamental problems in biochemistry: using studies on purple bacterial antenna complexes as an example // Biochem. J. - 2009. - V. 422, N 2. - P. 193-205.

30. Strümpfer J., Schultena K. Light harvesting complex II B850 excitation dynamics // J. Chem. Phys. - 2009. -V. 131, N 22. P. 225101-225101.

31. Koolhaas M.H.C., Zwan G. van der, Grondelle $R$. van. Local and nonlocal contributions to the linear spectroscopy of light-harvesting antenna systems // J. Phys. Chem. B. - 2000. - V. 104, N 18. - P. 4489-4502.

32. Blaber M.G., Arnold M.D., Ford M.J. Designing materials for plasmonic systems: the alkali-noble intermetallics // J. Phys.: Condens. Matter. - 2010. - V. 22, N 11. P. 095501(1-8).

33. Cao M., Wang M., Gu N. Optimized surface plasmon resonance sensitivity of gold nanoboxes for sensing applications // J. Phys. Chem. C. - 2009. - V. 113, N 34. P. 1217-1221.

34. Westcott S.L., Jackson J.B., Radloff C., Halas N.J. Relative contributions to the plasmon lineshape of metal nanoshells // Phys. Rev. B. - 2002. - V.66, N 15. P. 155431-155434.

35. Qian X, Park H.S. The influence of mechanical strain on the optical properties of spherical gold nanoparticles // J. Mech. Phys. Solids. - 2010. - V. 58, N 3. - P. 330-345.

36. Pullerits T., Visscher K.J., Hess S. et al. Energy transfer in the inhomogeneously broadened core antenna of purple bacteria: a simultaneous fit of low intensity picosecond absorption and fluorescence kinetics // Biophys. J. - 1994. - V. 66, N 1. - P. 236-248.

37. Nagarajan $V$. Parson $W . W$. Excitation energy transfer between the B850 and B875 antenna complexes of Rhodobacter sphaeroides // Biochemistry. - 1997. - V. 36, N 8. - P. 2300-2306.

Received 13.12.2012, accepted 25.02.2013 


\title{
Вплив золотої нанооболонки на збирання світла LH2 комплексом фотосинтетичних бактерій
}

\author{
І.Ю. Голіней, В.Й. Сугаков, Г.В. Верцімаха
}

Інститут ядерних досліджень Наџіональної академії наук України nросn. Науки, 47, Київ, 03680, Україна, avertsim@kinr.kiev.ua

Теоретично досліджено вплив присутності золотої нанооболонки поблизу периферичного світлозбирального комплекса LH2 фотосинтетичних бактерій на ефективність проиесів фотосинтезу. Визначений сумарний ефект обумовлений співвідношенням підсилення поглинання світла у смузі В850 внаслідок сильної взаємодії екситонів LH2-кільия та станів поверхневих плазмонів $і$ додаткового гасіння збуджень поблизу металу. Визначено діапазон параметрів гібридної системи, для яких присутність золотої нанооболонки веде до підвищення ефективності збирання світла.

\section{Влияние золотой нанооболочки на светособирание LH2 комплексом фотосинтетических бактерий}

\author{
И.Ю. Голиней, В.И. Сугаков, А.В. Верцимаха
}

Институт ядерних исследований Наџиональной академии наук Украины nросn. Науки, 47, Киев, 03680, Украина, avertsim@kinr.kiev.ua

Теоретически исследовано влияние присутствия золотой нанооболочки вблизи периферического светособирающего комплекса (LH2) фотосинтезирующих бактерий на эффективность процессов фотосинтеза. Определенный суммарный эффект обусловлен соотношением усиления поглощения света в полосе В850 вследствие сильного взаимодействия экситонов LH2-кольиа с состояниями поверхностных плазмонов и дополнительного гашения возбуждений вблизи металла. Определен диапазон параметров гибридной системы, при которых присутствие золотой нанооболочки приводит к увеличению эффективности светособирания. 